Check for updates

Cite this: RSC Adv., 2018, 8, 34000

Received 21st May 2018

Accepted 24th September 2018

DOI: $10.1039 / c 8 r a 04325 f$

rsc.li/rsc-advances

\section{Organocatalytic sulfa-Michael/aldol cascade: constructing functionalized 2,5-dihydrothiophenes bearing a quaternary carbon stereocenter $\phi$}

\author{
Xiao-Yu Zhu, (D) Mei-Heng Lv, Ya-Nan Zhao, Li-Yan Lan, Wen-Ze Li* and Lin-Jiu Xiao* \\ A practical sulfa-Michael/aldol cascade reaction of 1,4 -dithiane-2,5-diol and $\alpha$-aryl- $\beta$-nitroacrylates has \\ been developed, which allows efficient access to functionalized 2,5-dihydrothiophenes bearing \\ a quaternary carbon stereocenter in moderate to good yields with high enantioselectivities.
}

Among the various classes of heterocycles, members of the thiophene family have received particular attention from the chemical community because of their widespread occurrence as ubiquitous motifs in natural products, pharmaceuticals, agrochemicals as well as materials. ${ }^{1}$ In this context, the 2,5-dihydrothiophene ring is a common structural feature of many bioactive compounds and a potential intermediate for various synthetic applications. ${ }^{2}$ Over the decades, only a few examples of the assembly of optically active 2,5-dihydrothiophenes have been documented. ${ }^{3}$ For instance, the Spino ${ }^{3 b}$ group successfully prepared non-racemic dihydrothiophenes using an efficient chiral auxiliary. The first gold-catalyzed cycloisomerization of $\alpha$ hydroxyallenes to 2,5-dihydrothiophenes was reported by Krause $^{3 c}$ and co-workers. Then in 2010, the $\mathrm{Xu}^{3 e}$ group developed a highly stereoselective domino thia-Michael/aldol reaction between 1,4-dithiane-2,5-diol and $\alpha, \beta$-unsaturated aldehyde catalyzed by a chiral diphenylprolino TMS ether, which provided a new avenue for the synthesis of functionalized 2,5-dihydrothiophenes.

Quaternary carbon stereocenters are often contained in natural products and pharmaceuticals. ${ }^{4}$ Compared with the chiral pool synthesis, ${ }^{5}$ the procedure of chiral materials or catalysts to construct such sterically congested stereogenic centers is more challenging because of the difficulty of orbital overlap. ${ }^{6}$ To date, a lot of progresses have been made in the construction of chiral quaternary carbon centers in cyclic compounds, ${ }^{7}$ which are greatly accelerated by the advancement of transition metal catalysis, ${ }^{8}$ and organocatalysis, ${ }^{9}$ including methods beyond radical initiation. ${ }^{10}$ However, only few examples are about the construction of a quaternary carbon in 2,5dihydrothiophene ring. ${ }^{11}$ Inspired by the previous work of the $\mathrm{Xu}$ group, ${ }^{3 e}$ we describe herein an elegant organocatalytic

College of Applied Chemistry, Shenyang University of Chemical Technology, Shenyang 110142, China. E-mail: liwenze@syuct.edu.cn

$\dagger$ Electronic supplementary information (ESI) available. CCDC 869512. For ESI and crystallographic data in CIF or other electronic format see DOI: $10.1039 / \mathrm{c} 8 \mathrm{ra} 04325 \mathrm{f}$ asymmetric cascade sulfa-Michael/aldol reaction, providing a convenient way for the synthesis of 2,5-dihydrothiophenes bearing a chiral quaternary cabon center.

\section{Results and discussion}

At the outset of our pursuit, a series of organocatalysts I-VII were examined in the cascade reaction of 1,4-dithiane-2,5-diol 1a and $\alpha$-phenyl- $\beta$-nitroacrylate $\mathbf{2 a}$ in chloroform at room temperature (Fig. 1). The desired 2,5-dihyrothiophene 3a could be successfully obtained in the presence of cinchona alkaloid $\mathbf{I}$ within 24 hours in $40 \%$ yield with only $12 \%$ ee (Table 1 , entry 1 ). A substantial increase of yield and enantioselectivity were observed when thiourea-tertiary amine catalysts II-V were employed (Table 1, entries 2-5). Further optimization indicated that cinchona-based squaramide VI and VII with stronger $\mathrm{H}^{-}$ bonding donors gave the products with comparable results
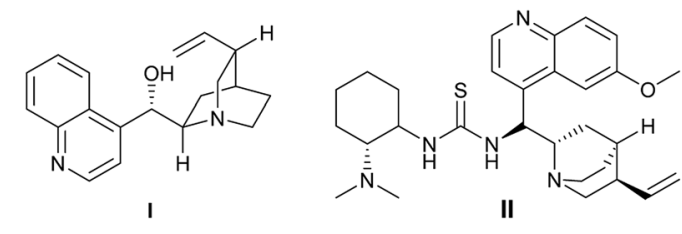<smiles>CN(C)[C@@H]1CCCC[C@H]1NC(=S)Nc1cc(C(F)(F)F)cc(C(F)(F)F)c1</smiles>

III<smiles>[R]c1ccc(NC(=S)N[C@H](c2ccnc3ccccc23)[C@@H]2C[C@@H](C=C)[C@@H](C)CN2)cc1</smiles>

IV: $\mathrm{R}=3,5-2 \mathrm{CF}_{3}$ V: $\mathrm{R}=3,5-2 \mathrm{CH}_{3}$

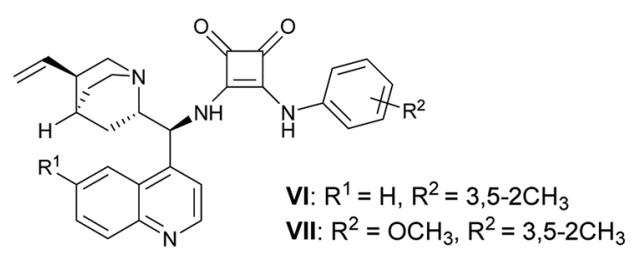

Fig. 1 The organocatalysts tested in this study. 
Table 1 Optimization of the reaction conditions ${ }^{a}$

\begin{tabular}{llllll}
\hline & & & \multicolumn{2}{l}{ 1) Cat. (10 mol\%) } \\
solvent, $25^{\circ} \mathrm{C}$
\end{tabular}

${ }^{a}$ Reaction conditions (unless otherwise stated): $1 \mathrm{a}(0.18 \mathrm{mmol}), \mathbf{2 a}(0.3$ $\mathrm{mmol})$, catalyst $(10 \mathrm{~mol} \%)$, solvent $(2 \mathrm{~mL}), T_{1}=25{ }^{\circ} \mathrm{C}$; then trifluoroacetic anhydride (TFAA, $0.6 \mathrm{mmol}), \mathrm{Et}_{3} \mathrm{~N}(0.6 \mathrm{mmol}), T_{2}=$ $0{ }^{\circ} \mathrm{C}$. ${ }^{b}$ Isolated yield based on 2a. ${ }^{c}$ Determined by chiral HPLC

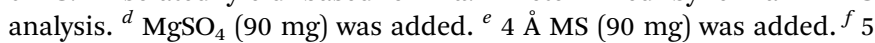
$\AA$ MS (90 mg) was added. ${ }^{g} T_{1}=15^{\circ} \mathrm{C}^{h}{ }^{h} T_{1}=0{ }^{\circ} \mathrm{C}, \mathrm{ND}=$ not determined.

(Table 1, entries 6 and 7), then we selected VII as the optimal catalyst. Next, changing chloroform to other solvents resulted in an obvious decrease both in yield and stereoselectivity (Table 1 , entries 8-13). To our delight, the addition of $\mathrm{MgSO}_{4}$ or molecular sieve (MS) into the reaction mixture could bring out a slight increase of the enantioselectivity, while the $5 \AA$ MS gave the best results (Table 1, entry 16). We also tried to set up the reaction under a lower temperature, the cycloadduct 3a could maintain the yield and enantioselectivity within a longer time at $15{ }^{\circ} \mathrm{C}$ (Table 1, entry 17). When the temperature was further decreased to $0{ }^{\circ} \mathrm{C}$, the reaction became very slow, and we only observed trace amount of product after 120 hours (Table 1, entry 18).

With the optimal conditions in hand, the cascade reaction of 1,4-dithiane-2,5-diol and diverse $\alpha$-aryl- $\beta$-nitroacrylates was investigated. The results were summarized in Table 2 . We found that $\alpha$-phenyl- $\beta$-nitroacrylates with different ester groups, including benzyl, isopropyl, tert-butyl, could react smoothly to give the desired chiral dihydrothiophenes in $67-73 \%$ yields with $66-83 \%$ ee (entries 1-3), while bulky tert-butyl group gave the best results (entry 3). The position and nature of substituents on the $\alpha$-phenyl ring had slight influence on the stereocontrol, $65-75 \%$ yields and $82-86 \%$ ee were observed (entries $4-9$ ). The reaction was also applicable to $\alpha$-naphthyl and furanyl nitroacrylates, producing the desired adducts with $83 \%$ and $85 \%$ ee,
Table 2 Scope for the synthesis of 2,5-dihydrothiophenes bearing a quaternary carbon stereocenter ${ }^{a}$

\begin{tabular}{|c|c|c|c|c|c|c|c|c|}
\hline & 1 & + & $\mathrm{NO}_{2}^{\mathrm{CO}_{2} \mathrm{R}^{3}}$ & $\begin{array}{l}\text { 1) } \mathrm{VI} \\
5 \AA \mathrm{N} \\
\mathrm{CHC} \\
\text { 2) } \mathrm{TF} \\
\mathrm{Et}_{3} \mathrm{~N} \\
\mathrm{CHC}\end{array}$ & $\begin{array}{l}(10 \mathrm{~m} \\
\mathrm{S}(45 \\
{ }_{3}, 25^{\circ} \\
\text { AA (2 } \\
(2 \text { equ } \\
{ }_{3}, 0^{\circ} \mathrm{C}\end{array}$ & $\begin{array}{l}\mathrm{ol} \%) \\
\mathrm{mg} / \mathrm{mL} \text { ) } \\
\mathrm{C} \\
\text { equiv) } \\
\text { iv) } \\
;\end{array}$ & $\rightarrow \sum_{S}^{R^{1}}$ & \\
\hline Entry & Product & $\mathrm{R}^{1}$ & $\mathrm{R}^{2}$ & & $\mathrm{R}^{3}$ & $t(\mathrm{~h})$ & Yield $^{b}(\%)$ & $\mathrm{ee}^{c}(\%)$ \\
\hline 1 & $3 \mathbf{b}$ & $\mathrm{H}$ & $\mathrm{Ph}$ & & $\mathrm{Bn}$ & 24 & 68 & 66 \\
\hline 2 & $3 c$ & $\mathrm{H}$ & $\mathrm{Ph}$ & & i-Pr & 24 & 67 & 80 \\
\hline 3 & $3 d$ & $\mathrm{H}$ & $\mathrm{Ph}$ & & $t-\mathrm{Bu}$ & 24 & 73 & 83 \\
\hline 4 & $3 e$ & $\mathrm{H}$ & $4-\mathrm{CH}_{3} \mathrm{C}_{6} \mathrm{I}$ & & $t-\mathrm{Bu}$ & 36 & 65 & 86 \\
\hline 5 & $3 f$ & $\mathrm{H}$ & $4-\mathrm{OCH}_{3} \mathrm{C}$ & ${ }_{6} \mathrm{H}_{4}$ & $t-\mathrm{Bu}$ & 24 & 71 & 82 \\
\hline 6 & $3 g$ & $\mathrm{H}$ & $4-\mathrm{FC}_{6} \mathrm{H}_{4}$ & & $t-\mathrm{Bu}$ & 24 & 68 & 85 \\
\hline 7 & $3 \mathbf{h}$ & $\mathrm{H}$ & $4-\mathrm{ClC}_{6} \mathrm{H}_{4}$ & & $t-\mathrm{Bu}$ & 24 & 75 & 86 \\
\hline 8 & $3 \mathbf{i}$ & $\mathrm{H}$ & $3-\mathrm{OCH}_{3} \mathrm{C}$ & ${ }_{6} \mathrm{H}_{4}$ & $t-\mathrm{Bu}$ & 24 & 74 & 84 \\
\hline 9 & $3 \mathbf{j}$ & $\mathrm{H}$ & $3,5-2 \mathrm{CH}_{3}$ & $\mathrm{C}_{6} \mathrm{H}_{3}$ & $t-\mathrm{Bu}$ & 30 & 67 & 83 \\
\hline 10 & $3 \mathbf{k}$ & $\mathrm{H}$ & 2-Naphth & & $t-\mathrm{Bu}$ & 24 & 72 & 86 \\
\hline 11 & 31 & $\mathrm{H}$ & 2-Furany & & $t-\mathrm{Bu}$ & 24 & 62 & 83 \\
\hline 12 & $3 m$ & $\mathrm{H}$ & i-Pr & & $t-\mathrm{Bu}$ & 24 & 69 & 85 \\
\hline $13^{d}$ & $3 n$ & $\mathrm{CO}_{2} \mathrm{Et}$ & $\mathrm{Ph}$ & & $t-\mathrm{Bu}$ & 36 & 65 & 87 \\
\hline $14^{d}$ & 30 & $\mathrm{CO}_{2} \mathrm{Et}$ & $3,5-2 \mathrm{CH}_{3}$ & $\mathrm{C}_{6} \mathrm{H}_{3}$ & $t-\mathrm{Bu}$ & 36 & 64 & 88 \\
\hline
\end{tabular}

${ }^{a}$ Reaction conditions (unless otherwise stated): 1 (0.18 mmol), 2 (0.3 mmol), VII (10 mol\%), $5 \AA$ MS (90 mg), $\mathrm{CHCl}_{3}(2 \mathrm{~mL}), T_{1}=25{ }^{\circ} \mathrm{C}$; then TFAA $(0.6 \mathrm{mmol}), \mathrm{Et}_{3} \mathrm{~N}(0.6 \mathrm{mmol}), T_{2}=0{ }^{\circ} \mathrm{C} .{ }^{b}$ Isolated yield based on $2 .{ }^{c}$ Determined by chiral HPLC analysis. ${ }^{d} T_{1}=-40{ }^{\circ} \mathrm{C}$.

respectively, the yields were also satisfactory (entries 10 and 11). Gratifyingly, branched as well as aliphatic nitroacrylate is equally suitable substrate (entry 12). In addition, we tried the reaction of 2,5-dihydroxy-1,4-dithiane-2,5-dicarboxylate with $\alpha$-aryl- $\beta$-nitroacrylates 2 n and $2 \mathbf{o}$, which exhibited promising results, leading to $64-65 \%$ yields and $87-88 \%$ ee at $-40{ }^{\circ} \mathrm{C}$ within 36 hours (entries 13 and 14).

To determine the absolute configuration of the products, we carried the cascade reaction in a large amount, and a single crystal of the optically pure product 3 a was obtained after crystallization, ${ }^{12}$ which was then determined to be $\mathrm{S}$ by X-ray crystallographic analysis. ${ }^{13}$ Based on the experimental result and previous studies, ${ }^{14}$ the transition state is shown in Scheme 1. Mechanistically, the $\beta$-nitroacrylate was activated by the hydrogen bonds of the squaramide, while the tertiary amine of the catalyst would enhance the nucleophilicity of mercaptoacetaldehyde based on its basicity, the nucleophile attacked the Michael acceptor from the Si face, which favoured the formation of the C2 (S) stereogenic center. It is worth noting that the prediction of possible interaction in the transition state was in agreement with the DFT calculation (Fig. 2). ${ }^{15}$

Because of the highly functionalization of the product, we also tried the synthetic transformation of 2,5-dihydrothiophene. Taking the reaction of $\mathbf{1 a}$ and $\mathbf{2 d}$ as example, when the addition and dehydration steps completed at the optimal conditions, the benzotriazole was added directly to the mixture as a nucleophile. Interestingly, the adduct 4 was 

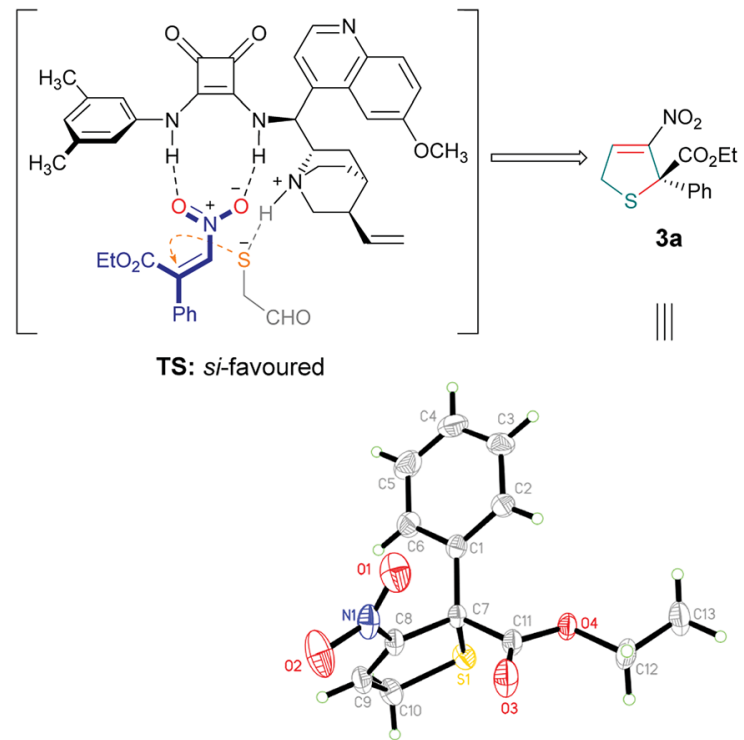

Scheme 1 Proposed transition state and the X-ray structure of 3a.

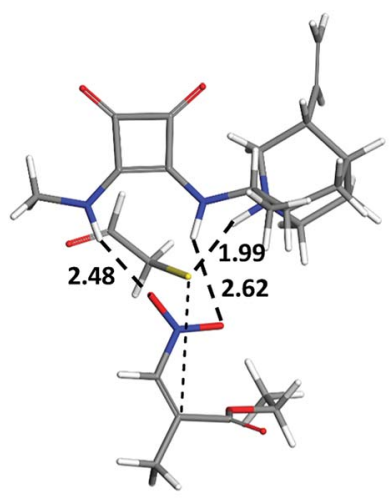

TS (a)

$0.0 \mathrm{kcal} / \mathrm{mol}$

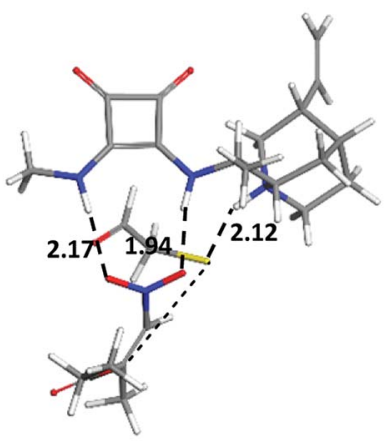

TS (b) $0.58 \mathrm{kcal} / \mathrm{mol}$
Fig. 2 Optimized structures and free energy gap of the transition states.

obtained with moderate yield and high stereoselectivities (eqn (1), $58 \%$ yield, $>19: 1 \mathrm{dr}, 85 \%$ ee).${ }^{16}$

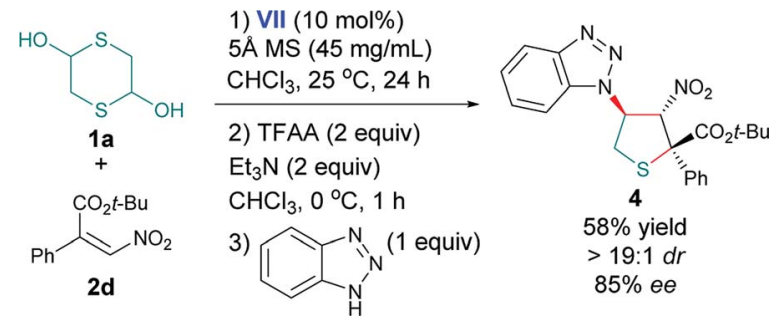

\section{Conclusions}

In summary, we have developed a practical sulfa-Michael/aldol cascade reaction of 1,4 -dithiane-2,5-diol and $\alpha$-aryl- $\beta$ - nitroacrylates, which allows an efficient access to functionalized 2,5-dihydrothiophenes bearing a quaternary carbon center in moderate to good yields with high enantioselectivities. Moreover, the products can be easily derivated to more complex compound. Further application of this strategy to the enantioselective synthesis of other heterocyclic systems is underway in our laboratory.

\section{Conflicts of interest}

There are no conflicts to declare.

\section{Acknowledgements}

We gratefully acknowledge the National Science Foundation of China (21502118) for financial support.

\section{Notes and references}

1 (a) A. Acharya, G. Parameshwarappa, B. Saraiah and H. Ila, J. Org. Chem., 2015, 80, 414; (b) A. Acharya, V. Gautam and H. Ila, J. Org. Chem., 2017, 82, 7920.

2 (a) E. Rogers, H. Araki, L. A. Batory, C. E. Mclnnis and J. T. Njardarson, J. Am. Chem. Soc., 2007, 129, 2768; (b) P. G. McGarraugh and S. E. Brenner, Org. Lett., 2009, 11, 5654; (c) S. Benetti, C. De Risi, G. P. Pollini and V. Zanirato, Chem. Rev., 2012, 112, 2129; (d) C. De Risi, S. Benetti, M. Fogagnolo and V. Bertolasi, Tetrahedron Lett., 2013, 54, 283; (e) A. Zaghi, T. Bernardi, V. Bertolasi, O. Bortolini, A. Massi and C. De Risi, J. Org. Chem., 2015, 80, 9176.

3 (a) G. Spagnol, M.-P. Heck, S. P. Nolan and C. Mioskowski, Org. Lett., 2002, 4, 1767; (b) J. Minville, M. Girardin and C. Spino, Can. J. Chem., 2007, 85, 603; (c) N. Morita and N. Krause, Angew. Chem., Int. Ed., 2006, 45, 1897; (d) N. Krause, V. Belting, C. Deutsch, J. Erdsack, H.-T. Fan, H. B. Gockel, A. Hoffmann-Röder, N. Morita and F. Volz, Pure Appl. Chem., 2008, 80, 1063; (e) J. Tang, D.-Q. Xu, A.-B. Xia, Y.-F. Wang, J.-R. Jiang, S.-P. Luo and X.-Y. Xu, Adv. Synth. Catal., 2010, 352, 2121; (f) Y. Xiang, J. Song, Y. Zhang, Y. D.-C. Yang, Z. Guan and Y.-H. He, J. Org. Chem., 2016, 81, 6042.

4 D. J. Newman and G. M. Cragg, J. Nat. Prod., 2016, 79, 629. 5 (a) H. X. Ding, C. A. Leverett, R. E. Kyne, K.-C. K. Liu, S. J. Fink, A. C. Flick and C. J. O'Donnell, Bioorg. Med. Chem., 2015, 23, 1895; (b) T. P. Stockdale and C. M. Williams, Chem. Soc. Rev., 2015, 44, 7737.

6 J.-J. Feng, M. Holmes and M. J. Krische, Chem. Rev., 2017, 117, 12564.

7 For selected reviews, see: (a) L. M. Repka and S. E. Reisman, J. Org. Chem., 2013, 78, 12314; (b) K. W. Quasdorf and L. E. Overman, Nature, 2014, 516, 181; (c) T. Ling and F. Rivas, Tetrahedron, 2016, 72, 6729; (d) M. Büschleb, S. Dorich, S. Hanessian, D. Tao, K. B. Schenthal and L. E. Overman, Angew. Chem., Int. Ed., 2016, 55, 4156; (e) H.-L. Li and Y.-X. Lu, Asian J. Org. Chem., 2017, 6, 1130. 
8 For selected recent examples, see: $(a)$ J.-W. Park, Z.-W. Chen and V. M. Dong, J. Am. Chem. Soc., 2016, 138, 3310; (b) Z.-S. Chen, X.-Y. Huang, J.-M. Gao and K.-G. Ji, Org. Lett., 2016, 18, 5876; (c) K. Balaraman and C. Wolf, Angew. Chem., Int. Ed., 2017, 56, 1390; (d) J.-W. Liu, Z.-B. Han, X.-M. Wang, F. Meng, Z. Wang and K.-L. Ding, Angew. Chem., Int. Ed., 2017, 56, 5050; (e) S.-Q. Xu, C. Wang, M. Komiyama, Y. Tomonari and E. Negishi, Angew. Chem., Int. Ed., 2017, 56, 11502; (f) J.-F. Zheng, L.-L. Lin, L. Dai, Q. Tang, X.-H. Liu and X.-M. Feng, Angew. Chem., Int. Ed., 2017, 56, 13107; (g) X.-W. Wu, B. Wang, Y. Zhou and H. Liu, Org. Lett., 2017, 19, 1294; $(h)$ Y. Ogiwara, K. Sato and N. Sakai, Org. Lett., 2017, 19, 5296; (i) M. A. Abozeid, S. Sairenji, S. Taizawa, M. Fujita and H. Sasai, Chem. Commun., 2017, 53, 6887; (j) L.-L. Hou, Y.-J. Yuan and X.-F. Tong, Org. Biomol. Chem., 2017, 15, 4803; (k) K. Li, F.-L. Zhu, Z.-T. Liu, J. Tong and X.-P. Hu, Org. Biomol. Chem., 2018, 16, 742.

9 For selected recent examples, see: $(a)$ B. M. Trost, T. Saget and C.-I. Hung, J. Am. Chem. Soc., 2016, 138, 3659; (b) C.-C. Zou, C.-K. Zeng, Z. Liu, M. Lu, X.-H. Sun and J.-X. Ye, Angew. Chem., Int. Ed., 2016, 55, 14257; (c) S. Bera, C. G. Daniliuc and A. Studer, Angew. Chem., Int. Ed., 2017, 56, 7402; (d) J.-Y. Liu, J. Zhao, J.-L. Zhang and P.-F. Xu, Org. Lett., 2017, 19, 1846; (e) S.-M. Yang, G. M. Reddy, T.-P. Wang, Y.-S. Yeh, M. Wang and W.-W. Lin, Chem.
Commun., 2017, 53, 7649; (f) L. Wang, A. Rahman and X.-F. Lin, Org. Biomol. Chem., 2017, 15, 6033; $(g)$ M. Zhao, J. Chen, H. Yang and L. Zhou, Chem.-Eur. J., 2017, 23, 2783; (h) J. Luo, Q.-X. Cao, X.-H. Cao and X.-D. Zhao, Nat. Commun., 2018, 9, 527; (i) Q. Li, L. Zhou, X.-D. Shen, K.-C. Yang, X. Zhang, Q.-S. Dai, H.-J. Leng, Q.-Z. Li and J.-L. Li, Angew. Chem., Int. Ed., 2018, 57, 1913; (j) G. Pandey, J. Khamrai and A. Mishra, Org. Lett., 2018, 20, 166; (k) A. Rahman, E. Xie and X.-F. Lin, Org. Biomol. Chem., 2018, 16, 1367.

10 For recent examples, see: $(a)$ N. S. Dange, F. Robert and Y. Landais, Org. Lett., 2016, 18, 6156; (b) S. Li, P.-P. Zhang, Y.-H. Li, S.-M. Lu, J.-X. Gong and Z. Yang, Org. Lett., 2017, 19, 4416; (c) H.-M. Huang, P. Bonilla and D. J. Procter, Org. Biomol. Chem., 2017, 15, 4159.

11 H. Kumamoto, T. Nakai, K. Haraguchi, K. T. Nakamura, H. Tanaka, M. Baba and Y.-C. Cheng, J. Med. Chem., 2006, 49, 7861.

12 See the ESI $\dagger$ for more details.

13 CCDC 869512 (for 3a) contains the supplementary crystallographic data for this paper.

14 H.-H. Lu, F.-G. Zhang, S.-W. Duan and W.-J. Xiao, Org. Lett., 2009, 11, 3946.

15 See the ESI† for details.

16 See the ESI $\dagger$ for more details. 